\title{
Effect of net shading technology on the yield quality and quantity of chilli pepper under greenhouse cultivation
}

\author{
Stella Agyemang Duah - Zsuzsa Nagy - Clarice Silva e Souza - Zoltán Pék - András Neményi - \\ Lajos Helyes
}

Department of Horticulture, Hungarian University of Agriculture and Life Sciences, 2100 Godollo Pater Karoly utca 1 Hungary agyemang.duah.stella@phd.uni-szie.hu

\section{SUMMARY}

\begin{abstract}
This study was undertaken to identify the effect of net shading technology on the total capsaicinoids, vitamin C and relative chlorophyll content expressed as SPAD (Soil Plant Analysis Development) values and total marketable fruit yield of 'Star Flame' chilli pepper (Capsicum annuum) for two harvesting times cultivated under modified atmosphere. 'Star Flame' pepper was grown under three (3) different net shading colours (white, red and green). Samples without net shading were used as control. Samples were subjected to chromatographic analyses using HPLC for the determination of total capsaicinoids and vitamin $C$. Interaction in shading technology and harvest times ( $p=0.010)$ had significant effect on total capsaicinoids as a result of green and white shading technologies showing higher differences when compared to control samples. Vitamin C content was observed to have increased in white and red shadings $(p=0.001)$ after the first harvest and gradually decreased after the second harvesting time $(p=0.002)$. Relative leaf chlorophyll content was significantly higher in white shading in the first and second harvest. Samples used as control had significantly higher marketable values when compared to white and green shadings with red recording low marketability of 'Star Flame' chilli peppers.
\end{abstract}

Keywords: Capsicum annuum; capsaicinoids; SPAD; vitamin C; yield

\section{INTRODUCTION}

Peppers belong to the family Solanaceae with Capsicum annuum as the most popular Capsicum sp. widely consumed by different countries (Mongkolporn, 2018). The record indicates that the history of chilli peppers can be traced to several locations in Mexico (Solomon et al., 2010) as well as other prominent pepper growing countries like China, Spain, Turkey and Indonesia. The chilli peppers contain different sources of antioxidant compounds, including capsaicinoids (Ochi et al., 2003; Topuz and Ozdemir, 2007) and flavonoids which is a type of phenolic compounds (Materska and Perucka, 2005). Capsaicinoids found in Capsicum sp. are vanillyl amides of a different division of fatty acids, with nine (9) to eleven (11) carbons of capsaicin and dihydrocapsaicin. Total capsaicinoids content is made up of about $60 \%$ capsaicin and $30 \%$ of dihydrocapsaicin (Topuz and Ozdemir, 2007). Capsaicinoids compounds are known for their therapeutic results on gastric ulcers and rheumatoid arthritis (Govindarajan and Sathyanarayana, 2009; Mason et al., 2004). Capsaicinoids also have pharmacological properties with a high content of capsaicin being medically beneficial in the treatment of painful conditions such as cluster headache, painful diabetic and neuropathy (Tsuchiya, 2001). They are also noted for decreasing myocardial and aortic cholesterol levels even when consumed at low levels in food. Currently, capsaicinoids have been studied and found to be an effective treatment for several human nerves disorder, including cystitis, arthritis and human immunodeficiency virus (Perucka and Materska, 2001; Robbins, 2000).

Vitamin C, also known as ascorbic acid, is a nutritional constituent of pepper fruit which is highly known biologically as an active compound which contain antioxidants (Rietjens et al., 2002). High levels of vitamin $\mathrm{C}$ can be found in fully ripened pepper fruits (Bae et al., 2014). However, vitamin C levels in pepper fruit vary from pepper cultivars and species to the other. Vitamin $\mathrm{C}$ is the most vital vitamin in fruits and vegetables necessary for human nutrition. Almost $90 \%$ of vitamin $\mathrm{C}$ in human food is obtained from fruits and vegetables (Lee and Kader, 2000).

Leaf chlorophyll concentration is an important parameter that is usually measured as an indicator of chloroplast development, photosynthetic capacity, leaf nitrogen content as well as general plant health. These transmittance values typically between 0.0 and 50.0 (Uddling et al., 2007) are proportional to the amount of chlorophyll in the sample which is relative SPAD meter device that is used to derive chlorophyll values (Limantara et al., 2015).

Abiotic stress can significantly affect photosynthetic activities of pepper plants, and therefore the use of chlorophyll fluorescence measurements can give a clear idea of plant health (Nagy et al., 2017). 'Star Flame' hybrid pepper cultivar (Capsicum annuum) is a yellow chilli pepper with a firm, long, thin-walled fruits. The yellow fraction or skin of 'Star Flame' pepper is mainly comprised of zeaxanthin, violaxanthin, antheraxanthin, $\beta$-cryptoxanthin, $\beta$-carotene and capsolutein (Hornero-Méndez et al., 2000) which contain capsaicinoids and vitamin C (Nagy et al., 2017). Levels of all these capsaicinoids can vary from one hybrid to the other, ripening stage or stage of maturity at harvest as well as storage and processing of these pepper fruits (Iqbal et al., 2013). 
Application of net shading is commonly used in areas or countries that are highly exposed to sunlight especially in the Mediterranean region of Europe (Legarrea et al., 2010) and in Hungary (Ombódi et al., 2016). This application is commonly used in the cultivation of bell peppers which influences fruit quality components and nutrients such as capsaicinoids, vitamin C, carotenoids (Nagy et al., 2015). However, in other varieties of Capsicum sp., application of net shading can be affected by total capsaicinoids which is dependent on temperature, fruit position on the plant, fruit maturation stage and the light intensity exposure (Butcher et al., 2012). There have been several studies that recorded the positive effect of using different net colour shadings in Capsicum annuum cultivars (Fallik et al., 2008; Goren et al., 2011; Kong et al., 2013).

The objective of this study was to determine the effect of net shading technology on total capsaicinoids, vitamin $\mathrm{C}$, relative chlorophyll content and total marketable fruit yield of 'Star Flame' hybrid chilli pepper (Capsicum annuum) cultivated under modified atmosphere/greenhouse.

\section{MATERIALS AND METHODS}

\section{Experimental Conditions}

The study was conducted at the experimental field of the Horticulture Institute, Hungarian University of Agriculture and Life Sciences, Gödöllö, Hungary (with latitude $47^{\circ} 61^{\prime} \mathrm{N}$, long. $19^{\circ} 32^{\prime} \mathrm{E}$ ) on sandy loam with $1.8-2 \%$ humus content and $\mathrm{pH}$ of 7. Capsicum annum 'Star Flame' hybrid seeds were purchased from Seminis in Kecskemét, Hungary. The seedlings were then transplanted into a $35 \mathrm{~m}$ (length) $\times 8 \mathrm{~m}$ (width) $\times 3 \mathrm{~m}$ (height) greenhouse in twin rows with a spacing of 0.4 $\mathrm{m}$ between plants and rows, and $0.8 \mathrm{~m}$ between twin rows. Irrigation was set-up using a drip system. All plants received an equal weekly application of Megasol (Yara Co., Hungary) that contained 16\% nitrogen $\left(\mathrm{NO}_{3}, \mathrm{NH}_{4}, \mathrm{NH}_{2}\right), 8 \%$ phosphorus $\left(\mathrm{P}_{2} \mathrm{O}_{5}\right), 24 \%$ potassium $\left(\mathrm{K}_{2} \mathrm{O}\right)$, and $8 \%$ sulphur $\left(\mathrm{SO}_{4}\right)$. Plant protection activities were carried out weekly throughout the study. Different sections of the greenhouse were covered with white, red and green coloured nets to alter the light environment leaving a non-shaded section in the same greenhouse used as control. Ten (10) plants with four (4) replicates were randomly selected for relative chlorophyll content (expressed as SPAD values). The experiment was carried out in 2017 with two (2) successive harvests. Fully ripened and healthy fruits in same replication were randomly selected for phytochemical (capsaicinoids and vitamin C) analyses and marketable quality pepper yield.

\section{Field Measurements}

\section{Relative Chlorophyll Content (SPAD value)}

Relative chlorophyll content or SPAD value meter measures the transmission of wavelengths of radiation through plant leaves. At the time of flowering and harvesting of the peppers, the SPAD index was determined with the use of a chlorophyll meter SPAD502 in fully new expanded leaf from the apex to the plant base in ten different pepper plants. The total production of fruits per plant was obtained 120 days after sowing, weighing the fruits throughout a $0.01 \mathrm{~g}$ precision analytical balance.

\section{Yield}

Harvesting was done by hand. Red ripen fruits were harvested in rows. Average fruit weight and yield $\left(\mathrm{t} \mathrm{ha}^{-1}\right)$ was measured using a weighing scale. The total weight of marketable fruits expressed as kilograms per square meter.

\section{Analytical Measurements \\ Total capsaicinoids content}

Total capsaicinoid content was determined and calculated as the sum of individual compounds that appeared on the chromatogram according to (Daood et al., 2015). About 3 grams of homogenised pepper fruit without seeds were crushed in a crucible mortar with quartz sand. About $50 \mathrm{~mL}$ of analytical-grade methanol was gradually added to the mixture. The mixture was subjected in an ultrasonic bath device for 3 minutes and then filtered through a filter paper. The filtrate was further purified by passing it through a $0.22 \mathrm{~mm}$ PTFE (Polytetrafluoroethylene Chromfilter) syringe filter before injection into an HPLC (High Performance Liquid Chromatography) column. For this, extracts were diluted appropriately and injected into a Nucleodur C18, Cross-Linked column. The separation was performed through isocratic elution using water and acetonitrile (50:50) and a flow rate of $0.8 \mathrm{~mL} \mathrm{~min}^{-1}$. The fluorometric capsaicinoid detection was carried out at two wavelengths (EX: $280 \mathrm{~nm}$ and EM: $320 \mathrm{~nm}$ ). Peaks corresponding to the different capsaicinoid compounds were identified by comparing retention times and mass data created by analysing the standard material.

\section{Vitamin C}

Vitamin $\mathrm{C}$ content was determined according to methods and HPLC protocols of Nagy et al. (2015). About 5 grams of homogenised pepper fruit (seed excluded) was crushed in a crucible mortar with quartz sand. $50 \mathrm{~mL}$ of $3 \%$ metaphosphoric acid solution was gradually added to the mixture. The mixture was filtered through a filter paper and further purified by passing it through a $0.45 \mathrm{~mm}$ cellulose acetate (Whatman) syringe filter before it was injected into an HPLC. For the quantitative determination of ascorbic acid, sample data were compared to that generated using standard materials (Sigma-Aldrich, Budapest, Hungary).

\section{Statistical Analyses}

Results were expressed using a one-way ANOVA to determine the effect of net shading on relative chlorophyll, total capsaicinoids and vitamin $\mathrm{C}$ content and investigated independently at each harvest time. Using a linear model, the effect of net shading on marketable yield of pepper was investigated in which 
yield and net shading were considered as the dependent variable and the explanatory variable, respectively. Pairwise comparisons were made via a Tukey HSD post-hoc test. Statistical analyses were performed using IBM SPSS 22 software (IBM, USA). Throughout the study, $\alpha$ was set at 0.05 .

\section{RESULTS AND DISCUSSION}

\section{Relative Chlorophyll Content (SPAD value)}

Chlorophyll content was found to be higher in the pepper plants under white net shading in the first and second harvest even though there was a general decrease in chlorophyll in all net shading plants, including control as indicated on Figure 1. SPAD values did not show significant differences in control, red and green net shaded plants, respectively. In agreement with previous studies by Shahak et al. (2008), moderate shade levels of $30-40 \%$ did not decrease an average of leaf chlorophyll content significantly, which was favourable for bell pepper plant growth. Leaves of the same age and position were found to respond to different light quality.

Figure 1. The effect of net shading and harvesting times on the Relative Chlorophyll content (expressed as SPAD values) \pm SD

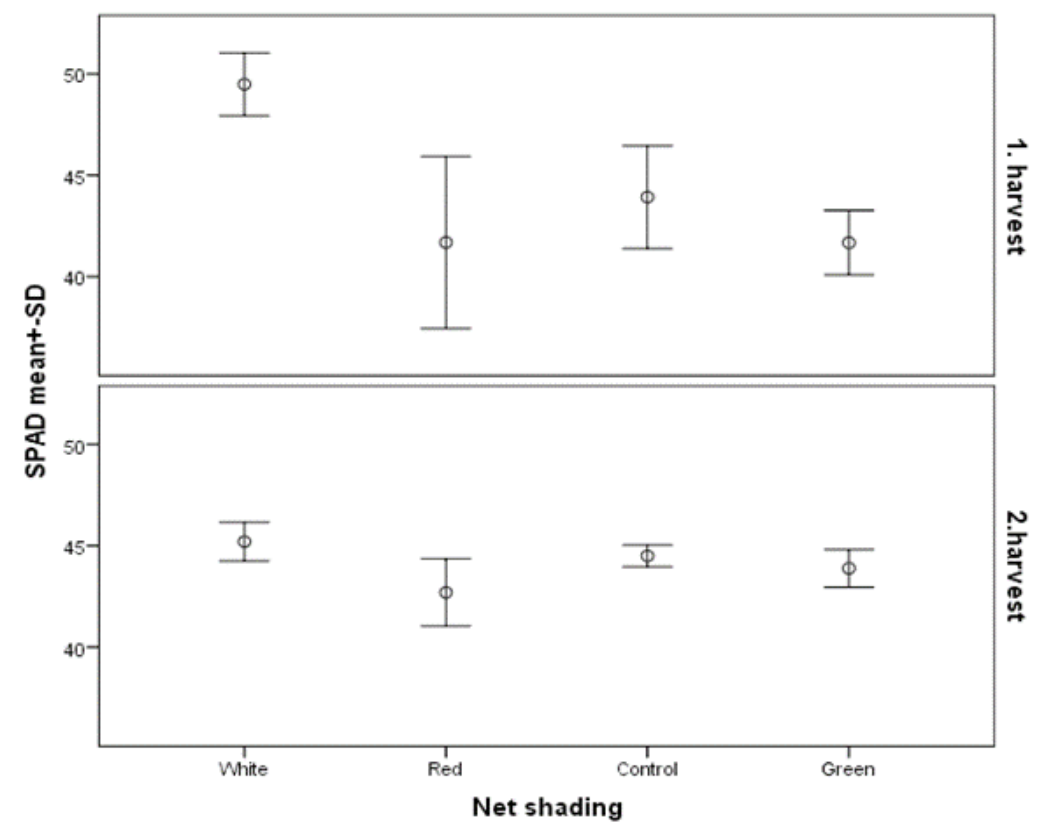

\section{Yield}

All net shading colours had some marketable yield or fruit quality (Table 1). Samples used as control recorded higher marketable yield with red net shading recording lower yield. Even though there was no significant difference between white and green net shadings, the use of green shading is not recommended for fruit marketability. This assertion corroborates with the findings of Ombódi et al. (2016) when PPFD (Photosynthetic Photon Flux Density) measured in the active photosynthetic range under green net shading and found that it had reduced more than those under white and red net shading. Unfavourable environmental conditions for pepper fruit ripening and reduction in PPFD could lead to lower pepper yields.
Table 1. The effect of net shading colour on total marketable yield of 'Star flame' hybrid chilli pepper. The yield expressed as kg $\mathbf{m}^{-2}$

\begin{tabular}{cc}
\hline $\begin{array}{c}\text { Net shading } \\
\text { colour }\end{array}$ & $\begin{array}{c}\text { Total } \\
\text { Marketable } \\
\text { Yield }\left(\mathbf{k g ~ m}^{-2}\right)\end{array}$ \\
\hline White & $2.63 \pm 0.60^{\mathrm{ab}}$ \\
Red & $2.10 \pm 0.30^{\mathrm{a}}$ \\
Green & $2.52 \pm 0.20^{\mathrm{ab}}$ \\
Control & $2.88 \pm 0.30 \mathrm{~b}$ \\
\hline
\end{tabular}

Means followed by the same letter in the lines, for each characteristic, did not differ statistically at Tukey HSD post-hoc tests at $\mathrm{p}=0.05$ 


\section{Total capsaicinoids concentration}

The results in comparison to control, green net shading indicated significantly $(\mathrm{p}<0.05)$ low content of capsaicinoids in the first harvest in July (Table 2). The impact of the use of red shading net in the second harvest in August indicated a significantly $(\mathrm{p}<0.05)$ lower capsaicinoids concentration. The increase in capsaicinoids in green net shading in the second harvest which could be as a result of temperature increase agrees with the investigation of Nagy et al. (2015). They reported that the increase in pepper pungency in green shading was as a result of higher night-time temperatures. Under greenhouse conditions in Israel, increased shading rate between 40 and $90 \%$ resulted with a higher flower abscission rate and reduced assimilation rates which differed among the cultivars (Aloni et al., 1996). Considerable differences between the harvesting times indicated that total capsaicinoids concentration was higher in the second harvest with white net shading showing increased response to pungency. The coloured shade nets has the best lightdiffusing capability in the PAR range, resulting in deeper light penetration into the canopy (Kong et al., 2013).

Table 2. The effect of net shading and harvesting times on the Total capsaicinoids of 'Star flame' pepper. The means are expressed in $\mu \mathrm{g} \mathrm{g}^{-1}$ fresh base weight $\pm \operatorname{SD}(n=4)$

\begin{tabular}{ccc}
\hline \multirow{2}{*}{ Net shading colour } & \multicolumn{2}{c}{ Harvesting times } \\
\cline { 2 - 3 } & $\mathbf{1}^{\text {st }}$ & $\mathbf{2}^{\text {nd }}$ \\
\hline White & $619.07 \pm 140.97^{\mathrm{Aab}}$ & $977.86 \pm 146.31^{\mathrm{Bb}}$ \\
Red & $516.79 \pm 74.80^{\mathrm{Aab}}$ & $559.14 \pm 60.01^{\mathrm{Aa}}$ \\
Green & $464.10 \pm 63.45^{\mathrm{Aa}}$ & $790.77 \pm 110.21^{\mathrm{Bb}}$ \\
Control & $661.89 \pm 32.80^{\mathrm{Ab}}$ & $830.72 \pm 78.69^{\mathrm{Bb}}$ \\
\hline
\end{tabular}

Means followed by the same letter in the lines, for each characteristic, did not differ statistically at Tukey HSD post-hoc tests at $\mathrm{p}=0.05$

\section{Vitamin C}

Application of different net shading on harvesting times indicated a general decrease of vitamin $\mathrm{C}$ by the second harvest in red and green net shadings (Table 3 ). White net shading was observed to have decreased in the second harvest instead. According to Kong et al. (2013), the use of white shading net has best lightdiffusing capability resulting in deeper light penetration into the plant canopy. The vitamin $\mathrm{C}$ content with a daily average greenhouse temperature of $22-28{ }^{\circ} \mathrm{C}$ after the first harvest could have stimulated its synthesis in the second harvest. Red net shading recorded lower vitamin $\mathrm{C}$ content both in the first and second harvest even though Ilić et al. (2011) asserted that the use of red net shading in the cultivation sweet peppers in greenhouses could enhance vitamin $\mathrm{C}$ content when compared to that of non-shaded peppers which did not corroborate to this study.

\section{Table 3. The effect of net shading and harvesting times on the vitamin $C$ content of 'Star flame' pepper. The means are expressed in $\mu \mathrm{g} \mathrm{g}^{-1}$ fresh base weight \pm SD $(n=4)$}

\begin{tabular}{ccc}
\hline \multirow{2}{*}{$\begin{array}{c}\text { Net shading } \\
\text { colour }\end{array}$} & \multicolumn{2}{c}{ Harvesting times } \\
\cline { 2 - 3 } white & $\mathbf{1}^{\text {st }}$ & $\mathbf{2}^{\text {nd }}$ \\
& $1918.59 \pm 102.74$ & $1805.37 \pm 43.07$ \\
red & $\mathrm{Bb}$ & $\mathrm{Ab}$ \\
& $1836.02 \pm 111.95$ & $1596.99 \pm 53.37$ \\
green & $\mathrm{Ba}$ & $\mathrm{Aa}$ \\
& $1686.98 \pm 30.20$ & $1650.24 \pm 144.84$ \\
Control & $\mathrm{Ba}$ & $\mathrm{Aa}$ \\
& $1769.40 \pm 31.75$ & $1739.50 \pm 87.27$ \\
& $\mathrm{Bab}$ & $\mathrm{Aab}$ \\
\hline
\end{tabular}

Means followed by the same letter in the lines, for each characteristic, did not differ statistically at Tukey HSD post-hoc tests at $\mathrm{p}=0.05$

\section{CONCLUSIONS}

The use of different net shading technology in 'Star flame' chilli pepper cultivated under greenhouse was investigated in this study. Both red and green net shadings showed a decrease in total capsaicinoids, vitamin $\mathrm{C}$, relative chlorophyll content and marketable yield. The use of white net shading in comparison to control in this study proved to be the best for chilli pepper grown under greenhouse environment. For sustainable and market-oriented benefits of chilli pepper production under greenhouse environment, further studies on different net colours could be investigated in the future.

\section{ACKNOWLEDGEMENTS}

This study was funded in part by Research Centre of Excellence- 9878-3/2016/FEKUT. The study was supported by Department of Horticulture, Szent Istvan University, Godollo and Tempus Public Foundation.

\section{REFERENCES}

Aloni, B.-Karni, L.-Zaidman, Z.-Schaffer, A.A. (1996): Changes of carbohydrates in pepper (Capsicum anпиит L.) flowers in relation to their abscission under different shading regimes. Ann. Bot., vol. 78, no. 2, pp. 163-168.

Bae, H.-Jayaprakasha, G.K.-Crosby, K.-Yoo, K.S.-Leskovar, D. I.Jifon, J.-Patil, B.S. (2014): Ascorbic acid, capsaicinoid, and flavonoid aglycone concentrations as a function of fruit maturity stage in greenhouse-grown peppers. J. Food Compos.
Anal., vol. 33, no. 2, pp. 195-202. doi: https://doi.org/10.1016/j.jfca.2013.11.009.

Butcher, J.D.-Crosby, K.M.-Yoo, K.S.-Patil, B.S.-Ibrahim, A.M. H.-Leskovar, D.I.-Jifon, J.L. (2012): Environmental and genotypic variation of capsaicinoid and flavonoid concentrations in Habanero (Capsicum chinense) peppers. HortScience, vol. 47, no. 5, pp. 574-579. doi: 10.21273/hortsci.47.5.574. 
Daood, H.G.-Halasz, G.-Palotás, G.-Palotás, G.-Bodai, Z.-Helyes, L. (2015): HPLC determination of capsaicinoids with crosslinked C18 column and buffer-free eluent. J. Chromatogr. Sci., vol. 53, no. 1, pp. 135-143. doi: 10.1093/chromsci/bmu030.

Fallik, E.-Alkalai-Tuvia, S.-Parselan, Y.-Aharon, Z.-Elmann, A.Offir, Y.-Matan, E.-Yehezkel, H.-Ratner, K.-Zur, N. (2008): Can colored shade nets maintain sweet pepper quality during storage and marketing? IV Balkan Symposium on Vegetables and Potatoes 830, Plovdiv, Bulgaria 2008; L. Krasteva, N. Panayotov; pp. 37-44.

Goren, A.-Alkalia-Tuvia, S.-Perzelan, Y.-Aharon, Z.-Fallik, E. (2011): Photoselective shade nets reduce postharvest decay development in pepper fruits. Adv. Hortic. Sci., pp. 26-31.

Govindarajan, V.S.-Sathyanarayana, M.N. (1991): Capsicumproduction, technology, chemistry, and quality. Part V. Impact on physiology, pharmacology, nutrition, and metabolism; structure, pungency, pain, and desensitization sequences. C R C Crit. Rev. Food Sci. Nutr., 29(6), 435-474.

Hornero-Méndez, D.-Gómez-Ladrón de Guevara, R.-MínguezMosquera, M.I. (2000): Carotenoid biosynthesis changes in five red pepper (Capsicum annиum L.) cultivars during ripening. Cultivar selection for breeding. J. Agric. Food Chem., vol. 48, no. 9, pp. 3857-3864.

Ilić, Z.-Milenković, L.-Đurovka, M.-Kapoulas, N. (2011): The effect of color shade nets on the greenhouse climate and pepper yield in Proceedings. $46^{\text {th }}$ Croatian and $6^{\text {th }}$ International Symposium on Agriculture, Opatija Croatia; 2011, pp. 529-532.

Iqbal, Q.-Amjad, M.-Asi, M.R.-Ariño, A. (2013): Characterization of capsaicinoids and antioxidants in hot peppers as influenced by hybrid and harvesting stage. Plant Foods Hum Nutri., 68(4), 358-363.

Kong, Y.-Avraham, L.-Perzelan, Y.-Alkalai-Tuvia, S.-Ratner, K.Shahak, Y.-Fallik, E. (2013): Pearl netting affects postharvest fruit quality in 'Vergasa' sweet pepper via light environment manipulation. Sci. Hortic., vol. 150, pp. 290-298. doi: https://doi.org/10.1016/j.scienta.2012.11.029.

Lee, S.K.-Kader, A.A. (2000): Preharvest and postharvest factors influencing vitamin $\mathrm{C}$ content of horticultural crops. Postharvest Biol. Technol.20(3), 207-220.

Limantara, L.-Dettling, M.-Indrawati, R.-Hardo, T.-Brotosudarmo, P. (2015): Analysis on the Chlorophyll Content of Commercial Green Leafy Vegetables Analysis on the Chlorophyll Content of Commercial Green Leafy Vegetables. Procedia Chem., vol. 14, no. April, pp. 225-231. doi: 10.1016/j.proche.2015.03.032.

Mason, L.-Moore, R.A.-Derry, S.-Edwards, J.E.-McQuay, H.J. (2004): Systematic review of topical capsaicin for the treatment of chronic pain. Br. Med. J., vol. 328, no. 7446, pp. 991-994. doi: 10.1136/bmj.38042.506748.ee.

Materska, M.-Perucka, I. (2005): Antioxidant Activity of the Main Phenolic Compounds Isolated from Hot Pepper Fruit (Capsicum аппиит L.). J. Agric. Food Chem., vol. 53, no. 5, pp. 1750-1756. doi: $10.1021 / \mathrm{jf} 035331 \mathrm{k}$.

Mongkolporn, O. (2018): Capsicum: Breeding Strategies for Anthracnose Resistance. CRC Press. https://books.google.hu/books?id=vQhpDwAAQBAJ
Nagy, Z.-Daood, H.-Nemenyi, A. (2017): Impact of Shading Net Color on Phytochemical Contents in Two Chili Pepper Hybrids Cultivated Under Greenhouse Conditions. korean J. Hortic. Sci., vol. 35, no. 4, doi: 10.12972/kjhst.20170045.

Nagy, Z.-Daood, H.-Ambrózy, Z.-Helyes, L. (2015): Determination of Polyphenols, Capsaicinoids, and Vitamin C in New Hybrids of Chili Peppers. J. Anal. Methods Chem., vol. 2015, doi: 10.1155/2015/102125.

Ombódi, A.-Pék, Z.-Szuvandzsiev, P.-Lugasi, A.-Ledóné Darázsi, H.-Helyes, L. (2016): Effect of coloured shade nets on some nutritional characteristics of a kapia type pepper grown in plastic tunnel. Columella J. Agric. Environ. Sci., vol. 3, no. 2, pp. 2533.

Perucka, I.-Materska, M. (2001): Phenylalanine ammonia-lyase and antioxidant activities of lipophilic fraction of fresh pepper fruits Capsicum annum L. Innov. Food Sci. Emerg. Technol., vol. 2, no. 3, pp. 189-192. doi: 10.1016/S1466-8564(01)00022-4.

Rietjens, I.M.C.M.-Boersma, M.G.-de Haan, L.-Spenkelink, B.Awad, H.M.-Cnubben, N.H.P.-van Zanden, J.J.-van der Woude, H.-Alink, G.M.-Koeman, J.H. (2002): The pro-oxidant chemistry of the natural antioxidants vitamin C, vitamin E, carotenoids and flavonoids. Environ. Toxicol. Pharmacol., vol. 11, no. 3-4, pp. 321-333.

Robbins, W. (2000): Clinical applications of capsaicinoids. Clin. J. Pain, vol. 16, no. 2 Suppl, pp. S86-9.

Shahak, Y.-Gal, E.-Offir, Y.-Ben-Yakir, D. (2008): Photoselective shade netting integrated with greenhouse technologies for improved performance of vegetable and ornamental crops. International Workshop on Greenhouse Environmental Control and Crop Production in Semi-Arid Regions 797; 2008; pp. 7580 .

Solomon, S.-Daniel, J.S.-Sanford, T.J.-Murphy, D.M.-Plattner, G. K.-Knutti, R.-Friedlingstein, P. (2010): Persistence of climate changes due to a range of greenhouse gases. PNAS, 107(43), 18354-18359.

Ochi, T.-Takaishi, Y.-Kogure, K.-Yamauti, I. (2003): Antioxidant activity of a new capsaicin derivative from Capsicum аппиит. J. Nat. Prod., vol. 66, no. 8, pp. 1094-1096. doi: 10.1021/np020465y.

Topuz, A.-Ozdemir, F. (2007): Assessment of carotenoids, capsaicinoids and ascorbic acid composition of some selected pepper cultivars (Capsicum annuum L.) grown in Turkey. J. Food Compos. Anal., vol. 20, no. 7, pp. 596-602. doi: 10.1016/j.jfca.2007.03.007.

Tsuchiya, H. (2001): Biphasic membrane effects of capsaicin, an active component in Capsicum species. J. Ethnopharmacol., vol. 75, no. 2-3, pp. 295-299. doi: 10.1016/S0378-8741(01)002008.

Uddling, J.-Gelang-Alfredsson, J.-Piikki, K.-Pleijel, H. (2007): Evaluating the relationship between leaf chlorophyll concentration and SPAD-502 chlorophyll meter readings. Photosynth. Res., vol. 91, no. 1, pp. 37-46. doi: 10.1007/s11120006-9077-5. 
